\title{
Os DiReitos humanos e AS QUeStÕes de GÊNERO.
}

\author{
THE GENDER AND HUMAN RIGHTS ISSUES
}

\author{
Losandro Antonio Tedeschi* \\ losandrotedeschi@ufgd.edu.br \\ Ana Maria Colling** \\ acolling21@yahoo.com.br
}

RESUMO: Gênero e Direitos Humanos tem se demonstrado um problema de difícil solução nos últimos anos. A desigualdade de gênero é uma afronta à igualização proposta pelos Direitos Humanos desde a sua fundação no século XVIII. E esta desigualdade, o poder e o domínio de uns sobre outras tem também a sua história. A reivindicação de Direitos Humanos aplicados às mulheres ocorre porque até há pouco tempo não eram consideradas humanas, mas sim, filhas, esposas de humanos. Apesar disso, a questão de gênero, ou a reivindicação dos direitos humanos para as mulheres ainda está em construção. A violência contra as mulheres e contra os homossexuais, apresenta-se como um desafio a ser vencido para quem almeja uma sociedade mais justa e igualitária para todos e todas. $\mathrm{O}$ artigo busca analisar a conexão entre estudos feministas e de gênero e avaliar os sentidos e significados dessas categorias e a sua incidência na geração de mudanças legais e culturais orientadas à equidade de gênero e à expansão da cidadania das mulheres.

PalaVRAS-ChAVE: Feminismo; Gênero; Direitos Humanos;

ABSTRACT: In recent years, gender and human rights have been demonstrated a difficult issue to solve. The gender asymmetries are an affront to equalization thought, proposed by human rights since XVIII century. These inequality, power and domination to one under others are presented along the history. The human rights reclaim applied to women is necessary because until recent times they have not

\footnotetext{
* Doutor em Historia UFGD. Professor pesquisadora nacional senior CAPES na UFGD

** Doutora em História pela PUCRS (2000) com estágio na Universidade de Coimbra, Portugal. ProfessorA pesquisadora nacional senior CAPES na UFGD
} 
been considered humans, but women were considered daughters and wives that belonged to humans. Nevertheless, the gender issues, or the reclaim women's human rights are in process of construction. The violence against women and homosexuals is a challenge to overcome to whom longs for the justice and equality society to everybody. The article aims to analyze the link between feminist studies and gender to measure the meanings of this categories and its impact on legal and cultural changed pointed out to gender equality and increase the women's citizenship.

KEY-WORDS: Feminism; Gender; Human Rights;

Os debates sobre os direitos humanos são muito recentes no mundo ocidental. Apesar das normativas legais serem estabelecidas no século XIX, somente no século seguinte com o os horrores do holocausto na 2a guerra mundial, e as bombas atômicas em Hiroshima e Nagasaki é que a sociedade começou a debruçar-se efetivamente com a garantia dos direitos humanos. Apesar disso questão de gênero, ou a reivindicação dos direitos humanos para as mulheres ainda está em construção. A violência contra as mulheres e contra os homossexuais, apresenta-se como um desafio a ser vencido para quem almeja uma sociedade mais justa e igualitária para todos e todas.

A desigualdade de gênero é uma afronta à igualização proposta pelos Direitos Humanos desde a sua fundação no século XVIII. E esta desigualdade, o poder e o domínio de uns sobre outras tem também a sua história. A reivindicação de Direitos Humanos aplicados às mulheres ocorre porque até há pouco tempo não eram consideradas humanas, mas sim, filhas, esposas de humanos.

Os três principais documentos sobre os Direitos Humanos - Declaração dos Direitos da Virginia (EUA) de 1776 é uma declaração de direitos que abre caminho para a independência da América do Norte e que vai ser a inspiradora para o documento lançado após a Revolução Francesa 
- Declaração dos Direitos do Homem e do Cidadão. O terceiro documento lançado pela ONU em 1948 segue os anteriores em seus princípios gerais. Mas os três silenciam sobre as mulheres. Se os dois primeiros falam em Direitos do Homem o terceiro avança e fala em Direitos do ser humano.

Gênero e Direitos Humanos tem se demonstrado um problema de difícil solução. Quando a francesa Olympe de Gouges foi decapitada ao escrever a uma Declaração dos Direitos da Mulher e da Cidadã ficou explicito a quem se destinava a nova cidadania. $O$ documento da ONU também teve um endereço social e político. Nasce após a tragédia do holocausto. Os dados alarmantes e preocupantes da violência contra as mulheres coloca em suspeita todos artigos igualitários das Declarações que tratam de Direitos Humanos.

\section{A HISTÓRIA DOS DIREITOS}

Os Direitos Humanos, como entendemos hoje, tem uma história e ela é contada através de três documentos fundamentais tidos como textos fundadores: A Declaração da Independência dos EUA de 1776; a Declaração dos Direitos do Homem e do Cidadão de 1789 e a Declaração Universal dos Direitos Humanos decretada pela ONU em 1948. O primeiro documento é elaborado por Thomas Jefferson nos Estados Unidos após a independência da Inglaterra; o segundo, com muitas afinidades ao documento norteamericano, é consequência da Revolução Francesa e o terceiro um efeito da Segunda Guerra Mundial. Se a declaração francesa é semelhante á norteamericana, também o documento da ONU apresenta similaridades aos seus antecessores. Segundo Hunt,

Por quase dois séculos, apesar da controvérsia provocada pela Revolução Francesa, a Declaração dos Direitos do Homem e ,do Cidadão encarnou a promessa de direitos humanos universais. Em 1948, quando as Nações Unidas adotaram a Declaração Universal 
dos Direitos Humanos, o artigo 1a dizia: "Todos os seres humanos nascem livres e iguais em dignidade e direitos. Em 1789, o artigo 10 da Declaração dos Direitos do Homem e do Cidadão já havia proclamado; "os homens nascem e permanecem livres e iguais em direitos". Embora as modificações na linguagem fossem significativas, o eco entre os dois documentos é inequívoco. HUNT, 2009, p.15).

Embaladas pelo Iluminismo e a Ilustração, a Revolução Francesa (1789) e a Revolução Americana (1776) fundam os novos direitos civis. O que distingue as declarações do século XVIII é a sua abrangência. A ruptura histórica e política efetuada pela Revolução Francesa tenta ir além da proposta norte-americana com pretensões de universalidade. Ao lançar a Declaração dos Direitos do Homem e do Cidadão, a nova burguesia no poder ambiciona contemplar a humanidade como um todo: declaração dos direitos civis de todos homens, de todos os países, de todos os povos, de todas etnias.

Segundo os revolucionários franceses, por ser uma declaração de caráter universal, deve valer para todos os homens, independente de sua posição social. O artigo 4. e estabelece que "a liberdade consiste em poder fazer tudo que não prejudique o próximo: assim, o exercício dos direitos naturais de cada homem não tem por limites senão aqueles que asseguram aos outros membros da sociedade o gozo dos mesmos direitos. Estes limites apenas podem ser determinados pela lei", determinando que este novo conceito, o de igualdade, seria mesmo para todos.

Assim como o séc. XVIII produziu o novo sujeito de direitos, produziu também a idéia de felicidade como um projeto social. Anteriormente, através da revolução industrial o homem descobriu que a educação, a produção de alimentos, a fabricação de coisas que necessitava como tecidos, máquinas, etc., poderia ser uma possibilidade para todos. A produção de instrumentos para se viver melhor, acenava que a felicidade poderia ser universal. 
A ideia de felicidade para todos provocou a idéia da igualdade entre todos. Uma sociedade mais justa e igualitária era o sonho de intelectuais e filósofos da época. Liberdade, Igualdade, Fraternidade, conceitos que se transformaram em paradigmáticos após a Revolução Francesa, sintetizaram os direitos do novo cidadão e são as palavras de ordem contra as opressões passadas. Mas este modelo liberal para o Ocidente, designou ou relegou muitos à condição de desiguais. É a partir dessa Revolução que se construiu o modelo de cidadania que atravessou o ocidente e da qual muitos permaneceram excluídos.

ADeclaraçãodosdireitosdohomemedocidadãoéuniversalmente reconhecida como o momento fundador dos modernos direitos à liberdade e à igualdade. Michel Foucault identifica na tríade revolucionária, tão cara aos franceses, a delimitação de espaços e comportamentos a serem seguidos por todos os indivíduos como dispositivos de submissão: por trás da liberdade, grande reclusão; por trás da igualdade, a escravidão do corpo; por trás da fraternidade, a exclusão.

A Declaração das Nações Unidas antes de seu artigo 10 (num total de 30) diz que "todos os seres humanos nascem livres e iguais em dignidade e direitos. São dotados de razão e consciência e devem agir uns para com os outros num espírito de fraterniudade", seguindo os mesmos principios das declarações de 1776 e 1789. Numa alusão ao holocausto, marca em seu preâmbulo que

visto que o desrespeito e o desprezo pelos direitos humanos têm resultado em atos bárbaros que ofenderam a consciêncisa da humanidade e que o advento de um mundo em que os seres humanos tenham liberdade de expressão e crença e a liberdade de viver sem medo e privações foi proclamado como a aspiração mais elementar do homem comum (HUNT, 2009, p.229).

Se as declarações de 1776 e 1789 tem um problema de linguagem, utilizando a expressão "direitos do homem", criada por Rousseau, 
a declaração da ONU, avança e, em todo o seus texto, inclui todos os sujeitos, fala em "Direitos humanos".

Os direitos humanos requerem três qualidades: ser naturais (inerentes aos seres humanos), iguais (os mesmos para todo o mundo) e universais (aplicáveis em toda a parte). Segundo Lynn Hunt, acabou sendo mais fácil aceitar a qualidade natural dos direitos do que a sua igualdade ou universalidade. A igualdade e a universalidade de direistos ainda é um tema debatido no mundo inteiro. Mas segundo este autora,

nem, o caráter natural, a igualdade e a universalidade são suficientes. Os direistos humanos só se tornam significativos quando ganham conteúdo político. Não são os direitos de humanos num estado de natureza: são os direitos de humanos em sociedade. São os direitos humanos vis-à-vis uns aos outros. E são direitos que requerem uma participação ativa daqueles que os detêm (HUNT, 2009, p.19).

Uma das prerrogativas fundamentais da liberdade e da igualdade é a autonomia. No século XVIII, e ainda hoje, não se imagina que todas as pessoas sejam autônomas. Para isso duas qualidades estavam implicadas: a capacidade de raciocinar e a independência de decidir por conta pórpia. No século XVIII em especial, as crianças, os loucos, os escravos, os criados, os sem propriedade e as mulheres não tinham independência para serem autônomos. Todos os relacionados podiam um dia tornar-se autonomos, crescendo ou comprando sua liberdade. Apenas as mulheres não tinham nenhuma destas opções: eram definidas como inerentemente dependentes de seus pais e maridos pelos aparatos jurídicos.

Quando se dizia que todos são iguais perante a lei, contestava-se um sistema de valores carregado de privilégios adquiridos pelo nascimento. Abolidas as diferenças entre os três estados, muitas outras permaneceram, entre elas a desigualdade entre os sexos, distinguindo um mundo inferior doméstico para as mulheres frente ao mundo superior público próprio dos homens. 
A desigualdade entre homens e mulheres é uma marca cultural que aparece em todo o ocidente. Como afirma Michelle Perrot, tão longe quanto nosso olhar histórico alcança só enxergamos a dominação masculina. Se as mulheres, e também os homens, são simplesmente um efeito de práticas discursivas e não discursivas, como nos ensina Michel Foucault, reconhecer os discursos e as práticas que nomearam as mulheres, o lugar social, as tarefas, as atribuições, e também a subjetividade feminina é tarefa primeira para a democratização e a igualização nas relações entre os gêneros.

\section{A EXCLUSÃO DAS MULHERES}

Embora os revolucionários franceses reivindicassem a ideologia republicana fundada na liberdade e na igualdade dos cidadãos, não estendiam estes direitos às mulheres. Mirabeau, Danton e Robespierre, célebres figuras da Revolução, rejeitavam a idéia de uma hierarquia natural entre os homens, mas mantinham-se mudos em relação às mulheres. Muitas delas tentaram fazer-se ouvir, através da pena ou da palavra, gritando nas tribunas da Assembléia ou em manifestações de rua, mas eram escarnecidas, caricaturadas e desqualificadas. Propalava-se que as revolucionárias possuíam uma sensualidade desenfreada e uma violência incontrolável, para serem vistas como mulheres pouco respeitáveis e perigosas.

Em 1791, Olympe de Gouges, embalada pelos ideais libertários da Revolução, escreve a Declaração dos Direitos da Mulher, apresentada aos Estados Gerais, demonstrando a parcialidade do sujeito masculino e reivindicando que a diferença de sexo não pode justificar a exclusão das mulheres do poder político e da cidadania social. Olympe aceita o princípio da universalidade que está na base da declaração dos direitos do homem e reivindica a diferença que hoje definimos como de "gênero", fazendo de homens e de mulheres o fundamento da nação. A Declaração, constitui- 
se na primeira interrogação sobre o papel da mulher nas teorias e práticas institucionais e tenta demonstrar as capacidades intelectuais e racionais do gênero feminino:

Homem, sabes ser justo? É uma mulher que te pergunta: não quererás tolher-lhe esse direito. Dize-me, quem te deu o soberano poder de oprimir o meu sexo? (...) Extravagante, cego, desdenhoso da ciência e degenerado, neste século de luzes e de perspicácia, na mais crassa ignorância, quer imperar sobre um sexo que tem todas as faculdades intelectuais; que pretende aproveitar a Revolução e reclamar os seus direitos à igualdade, para não dizer mais. (...) Considerando que a ignorância, o esquecimento ou o desprezo dos direitos da mulher são as únicas causas das desventuras públicas e da corrosão dos governos, elas resolveram expor numa solene declaração os direitos naturais inalienáveis e sagrados da mulher...

A Declaração, um ato de fé na razão e na verdade, continha as seguintes reivindicações: direito ao trabalho nas oficinas de confecções e têxteis, direito à instrução e acesso a todas as carreiras, legislação melhorada para as mulheres abandonadas e mães solteiras, direito das mulheres disporem dos seus bens sem dar conta aos maridos. Pregava o divórcio e a igualdade cívica, dando às mulheres o direito de estarem representadas nos Estados Gerais. Os revolucionários recusam-se a atender suas reivindicações e uma delegação de mulheres foi expulsa do Conselho Geral.

Robespierre, referindo-se às revolucionárias que haviam lutado ao seu lado na derrubada do antigo regime, deixa escapar a sua misoginia: "As mulheres aceitam as novas idéias porque são ignorantes; espalham-nas facilmente porque são levianas e lutam por elas muito tempo porque são teimosas" (PALLA, 1985, p.28). No 9 de Brumário de 1793, a Convenção decide fechar os clubes fundados pelas mulheres e, quatro dias depois. Olympe é decapitada. A revolução inspirada em promessas libertadoras não altera o estatuto das mulheres, demonstrando que as diferenças de gênero e de seus papéis sociais são mais profundas e arraigadas que as diferenças políticas, econômicas e sociais. 
Assim como nem todas as mulheres aderiram ao ideário igualitário de Olympe de Gouges e outras revolucionárias, nem todos os homens portavam-se da mesma maneira que Danton e Robespierre. Jean Marie Condorcet, filósofo de concepções feministas, denunciou todas as formas de opressão sobre a mulher, considerando essencial a simetria entre os sexos em relação a todos os aspectos da vida social. Em sua obra Sur l'admission des femmes au droit de cité de 1790, questiona a exclusão das mulheres do direito de cidadania que, segundo ele, equivale a qualquer outra forma de discriminação, contrária ao espírito emancipador da revolução.

Pela primeira vez uma voz masculina vem se opor à farta argumentação sobre as razões "naturais" para a discriminação das mulheres. Quanto às justificativas da inferioridade feminina para excluir as mulheres, Condorcet arrolou-as e recusou-as uma a uma. Frente ao argumento fisiológico em relação à gestação, aleitamento e menstruação, que transformava a mulher em incapaz de exercer seus direitos cívicos, perguntava se privavase dos direitos políticos quem era acometido de gota regulamente ou que se resfriava facilmente. "Não violaram todos o princípio da igualdade dos direitos, privando tranqüilamente a metade do gênero humano daquele de concorrer para a formação das leis, excluindo as mulheres do direito de cidadania?"(CONDORCET, 1991,45).

Na discussão sobre a universalidade dos direitos do cidadão, a questão central era se a Declaração dos Direitos do Homem aplicava-se a todos os seres humanos, seja qual for o seu sexo, religião ou raça, ou se dizia respeito somente aos homens. Para subtrair às mulheres o exercício de seus direitos naturais, seria preciso primeiro provar que elas não pertenciam ao gênero humano. A posição de Condorcet é clara: “Ou nenhum indivíduo da espécie humana tem verdadeiros direitos, ou todos têm os mesmos; e aquele que vota contra o direito do outro, seja qual for sua religião, cor ou sexo, desde logo abjurou os seus". 
Quanto às justificativas da inferioridade feminina para excluir as mulheres, Condorcet arrolou-as e recusou-as uma a uma. Frente ao argumento fisiológico em relação à gestação, aleitamento e menstruação, que transformava a mulher em incapaz de exercer seus direitos cívicos, perguntava Condorcet se privava dos direitos políticos quem era acometido de gota regulamente ou que se resfriava facilmente. Diziam os contrários à participação feminina que as mulheres eram intelectualmente inferiores ao homem, mesquinhas, não conduzidas pela razão mas por suas paixões, sem sentido de justiça. ${ }^{1}$ Como lhes conceder o direito ao voto se dependem dos maridos? Perguntavam. Se votarem não terão uma influência desastrosa sobre os homens?

Entre todos os argumentos utilizados para afastar a mulher da política, para não lhe conceder o título de cidadã, o que mais pesava era o medo de que as mulheres abandonassem os deveres "que a natureza havia Ihe reservado". Se elas participassem da vida pública, quem cuidaria dos filhos e manteria o lar acolhedor? Condorcet defendia a educação às mulheres, porque, em sua opinião, somente uma sólida instrução podia tornar as mulheres aptas a exercerem os seus direitos: "não é a natureza, é a educação, é e existência social que causa essa diferença". Tenta, então, convencer seus colegas de que a instrução feminina reverteria em privilégios às crianças, ao esposo e à família. Não conseguiu adeptos entre os homens, e muitas mulheres burguesas também não concordavam com suas propostas, preferindo seguir a cartilha de Emílio e sua Sofia, de Rousseau, o porta-voz da liberdade, segundo elas. O que Rousseau fornecia, na verdade, era uma exemplar legitimação burguesa à subordinação da mulher no casamento.

Com a adesão das mulheres francesas à proposta da relação entre Emílio e Sofia, Condorcet desabafa:

tenho medo de me indispor com elas...falo de seus direitos, e não de seu império; podem suspeitar de minha vontade secreta de diminuílo; e depois que Rousseau mereceu a aprovação delas, dizendo que 
só eram feitas para cuidar de nós, e para nos atormentar, não devo esperar que elas se declarem a meu favor (CONDORCET, 1991, p.19).

A construção do cidadão e da não cidadã também tem sua história. No século XVIII, quando discute-se a cidadania dos indivíduos, o teórico europeu da igualdade, Jean-Jacques Rousseau, estabelece que a vida das mulheres está consagrada ao papel doméstico. O filósofo define que a existência feminina materializa-se nos olhos dos outros, (não é somente necessário ser honesta é preciso parecer honesta aos olhos dos outros) estabelecendo uma ligação entre a natureza e a moral da mulher. Rousseau referenda a feminilidade natural da mulher, a doçura, a modéstia, as atividades caseiras e propõe o enclausuramento feminino: "Só uma mulher deve mandar em casa. Mas deve limitar-se ao governo doméstico, não se meter com as coisas de fora, se manter encarcerada em casa" (Cf. BADINTER, 1991, p.20).

Rousseau exerceu enorme influência entre as mulheres especialmente pela sua obra pedagógica Emílio - da educação de 1762, sucesso de vendas, onde explicitava pedagogicamente o lugar social do feminino. Referenda a feminilidade natural da mulher, a doçura, a modéstia, as atividades caseiras e propõe o enclausuramento feminino. Discorria também sobre a educação dos filhos que deveriam receber carinho e cuidado. Quanto às mulheres, que devem ser educadas na vergonha e no pudor, seus conselhos não deixavam dúvida quanto ao lugar que deveriam ocupar na sociedade:

Quase todas as raparigas aprendem com repugnância a ler e escrever, mas quanto a segurar a agulha, é o que elas aprendem sempre de boa vontade. Antecipadamente imaginam-se crescidas e sonham com prazer que estes talentos poderão um dia servir-Ihes para se enfeitar. Aberto este primeiro caminho é então fácil de seguir: vêm por si mesmo a costura, o bordado, a renda (ROUSSEAU, 1992, p.178).

Elisabeth Badinter, em Palavras de Homens, analisa o lugar da mulher na sociedade segundo os revolucionários franceses, lembrando que 
o discurso dominante durante a Revolução Francesa, tributário a Rousseau, triunfará nas sociedades ocidentais até o fim da Segunda Guerra Mundial. A advertência de Rousseau de que a única chance de felicidade da mulher é abandonar o mundo exterior, sofrer em silêncio e dedicar a vida aos seus familiares teve boa acolhida entre as mulheres do mundo inteiro. A receita era seguir a função que a natureza lhe destinou, sob pena de ser anormal e infeliz. As mulheres não exercerão os direitos cívicos, não possuirão direitos humanos, já que a felicidade de todos, inclusive delas próprias, tem este preço, conclui o filósofo.

Em 1793 é publicado um texto na França, de autor desconhecido, que leva o sugestivo título de Lições a tirar da execução de três mulheres, que trata sobre o exemplo dado às mulheres, pelo Tribunal Revolucionário, na condenação de Maria Antonieta, Olympe de Gouges e madame Roland. Esclarecendo o que os revolucionários entendiam como cidadania, e a quem ela era destinada, o panfleto aconselha a todas a todas as mulheres:

Amai, segui e ensinai nas leis que chama de novo vossos esposos e vossos filhos ao exercício de seus direitos; glorificai-vos com as ações brilhantes que eles poderão realizar em favor da pátria, porque estas dão um testemunho a vosso favor; sede simples no vosso modo de trajar, laboriosas no vosso lar; jamais frequenteis as assembléias populares com o desejo de ali falar; mas que a vossa presença encoraje por vezes vossos filhos; então a pátria vos abençoará, porque tereis realmente feito por ela o que ela tem direito de esperar de vós (Cf. BADINTER, 1991, p.204).

Se no século XVIII Condorcet pode ser considerado como um dos únicos revolucionários e parlamentares a reconhecer a equivalência política entre os sexos, no século seguinte outros homens e mulheres juntaram-se a esta preocupação. John Stuart Mill, em seu livro Subjection of Women (escrito a quatro mãos com sua mulher Harriet Taylor), chamou a atenção para a alienação feminina: sem acesso ao poder político, as mulheres não teriam meios de garantir os outros direitos fundamentais para se tornarem sujeitos 
autônomos. O casamento igualitário de Mill e sua esposa foi severamente criticado por Freud em carta à sua noiva, demonstrando explicitamente a sua concepção do lugar destinado ao feminino.

Peter Gay, em biografia sobre o fundador da psicanálise, relata os termos desta correspondência, quando Freud acusa Mill de faltar com o senso de absurdo nas suas propostas sobre a igualdade entre os sexos. A destemperança de Mill, segundo o psicanalista, dá-se em vários aspectos, como, por exemplo, na emancipação das mulheres e na questão feminina em geral. A defesa de que as mulheres podiam ganhar tanto quanto os homens, revoltou Freud, porque isto "deixava de lado as realidades domésticas: manter a casa em ordem, supervisionar e educar os filhos constituem uma ocupação em tempo integral que praticamente impede o emprego da mulher fora de casa" ( GAY, 1994, p.52).

Nesta mesma carta, Freud afirma que as mulheres, ao contrário do que afirmava o ensaio de Mill, não são escravas brancas e, se soubessem do teor de suas propostas, "qualquer moça, mesmo sem direito de voto nem competência jurídica, cuja mão um homem beija e por cujo amor ele tudo ousa, tê-lo-ia corrigido". Segundo Freud, a emancipação total das mulheres significaria o fim de um ideal admirável. Conclui a carta, afirmando que a natureza destinou a mulher, através da beleza, do encanto, da doçura, a algo mais. Assume o seu ideal de feminilidade, dizendo à noiva: "Não, a este respeito sou antiquado, desejo a minha Marta como ela é, e ela própria não há de querer que seja diferente: ser uma namorada adorada na mocidade e uma esposa amada na maturidade" (GAY, 1994, p.52).

Segundo Mill, a sujeição das mulheres tem sido tão universal quanto a diferença entre os sexos. Considerava a situação social de inferioridade das mulheres como um problema político e social, descaracterizando a diferença biológica como origem da subordinação feminina. A sujeição das mulheres põe em dúvida o valor do conceito de democracia e, para Mill, 
esta só será alcançada através da democracia sexual, sobretudo na família. Perguntava ele: "è possível denominar democracia um sistema político que exclui as mulheres da cidadania, e portanto, da participação política?" (MILL, apud ALVAREZ, 1994).

Mill conclui enumerando os efeitos positivos que produzirá a igualdade dos sexos na sociedade: argumentos de índole moral - a igualdade dedos sexos é uma condição necessária para o desenvolvimento moral da humanidade, e de caráter consequencialista: "o desperdício do potencial de talentos naturais da metade da espécie aparece como um desperdício que a sociedade não pode permitir"(Cf. MILL, 2006).

As mulheres não podem participar da esfera pública, da cidadania, não porque são incapazes, mas porque são por "natureza" destinadas à esfera familiar e privada, para a qual possuem "virtudes"específicas, nasceram para estas virtudes e para os cuidados domésticos. A insistência sobre uma natureza feminina familiar e doméstica e uma natureza masculina social e política, foi abundante no discurso revolucionário que instalou a igualdade e a cidadania, deixando a impressão de que a própria natureza prescreveu para cada sexo as respectivas funções.

\section{DIREITOS HUMANOS NA LUTA CONTRA A VIOLÊNCIA}

As constituições estabelecem a igualdade como princípio fundamental vetando todas as distinções. Mas sabemos que a igualdade constitucional não acaba com a discriminação entre homens e mulheres que tem acompanhado a história da civilização. A desigualdade entre os sexos é historicamente construída e sua face mais cruel é a violência praticada contra a mulher. A violência contra a mulher é o atestado desrespeito às Direitos Humanos invocados por todas declarações. 
A Declaração dos Direitos do Homem e do Cidadão de 1789 como efeito da Revolução Francesa e a decapitação de Olympe de Gouges, acusada de ser duplamente traidora: traiu a natureza de seu sexo e quis ser um home de estado, se reveste de uma importância capital para a história das mulheres. Os códigos civis implantados em praticamente todo o ocidente são heranças do código napoleônico.

O Código de Napoleão de 1804, influenciou a condição da mulher, dando corpo a idéia de que a mulher é propriedade do marido, e que sua função primordial é gerar filhos. A mulher casada existe apenas na família e para a família, e é dela que tratam os códigos e é sobre ela que recaem diversos impedimentos, cristalizando sua dependência e justificando sua inferioridade. O Código napoleônico, encarnação da modernidade, editado logo após a Revolução Francesa, determinou por mais de um século a subordinação privada das mulheres e influiu decisivamente na negação à sua cidadania política.

O Código Civil brasileiro editado em 1917, assumiu as diretrizes do Código napoleônico, que legitimava o princípio da incapacidade civil das mulheres casadas, consideradas menores submetidas à autoridade do marido, desprovidas de todos os direitos políticos. O casamento, que através de vários discursos é elevado ao único ideal feminino, à única maneira de realização feminina como esposa e mãe, é, ao mesmo tempo, a gaiola da mulher; transforma-se na sujeição de um sexo pelo outro. Arranjar marido significava para a mulher perder a capacidade jurídica. O casamento privava-a de exercer os direitos pessoais e patrimoniais.

Com o casamento a mulher rebaixava-se à categoria de menor, dependente do marido, mas todas queriam casar-se, porque solteiras não eram bem vistas socialmente. Extremo paradoxo de considerar-se o estado da casada como o que oferece um maior status a uma mulher, ao mesmo tempo, como tal, sua capacidade e personalidade jurídica, já diminuída, 
fica consideravelmente reduzida. As mulheres eram, portanto, destinadas a viverem como menores de idade permanente.

O conceito de honra é inaugurado neste código e a honra da mulher é um dos principais motivos alegados para seu extermínio. Este conceito de honra é sexualmente localizado e o homem é o legitimador, uma vez que a honra é atribuída pela sua ausência, através da virgindade, ou pela presença no casamento. Os crimes em defesa da honra, são perpetrados e justificados tendo como base nestes códigos.

O princípio cristão "não matarás" não parece aplicar-se aos que assassinam suas esposas e companheiras. Esta decisão perpetua uma cultura de impunidades de assassinatos e agressões de esposas e amantes por parte de seus maridos e companheiros que causa perplexidade e indignação. Matava-se em nome do desprezo pela mulher e era absolvido em nome da "honra" calcado neste mesmo desprezo.

A tese jurídica da legítima Defesa da Honra deixou milhares de criminosos em liberdade, numa demonstração da conivência do estado com a violência doméstica e da persistência de uma hierarquia sexual. Alguns países chegavam a adotar a norma da impunidade total em favor do marido que "vingasse a honra" ao surpreender a mulher em adultério. No Brasil, de acordo com o Código penal de 1890, só a mulher era penalizada por adultério, sendo punida com prisão de 1 a três anos. O homem só era considerado adúltero se possuia concubina teúda e manteúda.

Cézare Lombroso, um criminologista italiano que exerceu influência nas leis jurídicas e criminológicas brasileiras, do final do século passado, apresentava a mulher como menos inteligente, menos sensível, com capacidade de se manter em castidade, condição impossível de exigirse dos homens. Com este raciocínio justificava que as leis do adultério só atingissem a mulher, cuja natureza não a predispunha a este tipo de transgressão. Portanto, se a mulher traía era porque era má, diferentemente 
do homem que somente obedecia a natureza de seu sexo. Por este motivo o adultério masculino diz respeito à ordem privada e o feminino transforma-se em transgressão pública.

A incapacidade da mulher, estabelecida pelo Código Civil é eliminada em 1962 com a edição do Estatuto da Mulher Casada. A cultura, as mentalidades durante muito tempo conservaram o estatuto da defesa da honra masculina. A Lei Maria da Penha², lei no 11.34 criada no Brasil em 7 de agosto de 2006, tem como principal objetivo combater a violência contra a mulher - questão de saúde pública e violadora dos direitos humanos.

Segundo dados da ONU, o Brasil aparece em 53 lugar no índice mundial de igualdade entre os gêneros. Na América latina aparece em $6^{\circ}$ lugar, seguindo o Uruguai, Argentina, Venezuela, Chile e Colômbia. Os dados levados em consideração pela ONU são a alfabetização, esperança de vida e economia. Mas, a face mais cruel da desigualdade é a violência praticada contra a mulher e encarada como natural por muitos.

Dez mulheres morrem por dia no Brasil vítimas de violência; a cada minuto uma mulher é vítima de estupro; a cada 2 minutos cinco mulheres são espancadas no Brasil. A violência contra a mulher é uma chaga mundial, acirrada ou radicalizada nos países latinos. Ela é tão preocupante que a Conferência realizada em Viena em 1993, além de repudiar e condenar veementemente todas as formas de violência contra a mulher, colocou-a no mesmo estatuto de importância de outras violações brutais dos direitos humanos como o genocídio, a limpeza étnica, as torturas, a discriminação racial e o terrorismo.

Não se pode entender a violência como uma questão privada, que deve ser tratada na intimidade do lar, pois ela demanda soluções no âmbito da saúde, educação, trabalho e segurança e essas são questões públicas e comunitárias. A violência doméstica deve ser tratada como uma questão criminal. Tornar este fenômeno visível aos olhos da sociedade é um 
primeiro passo para que medidas sejam implementadas, e o caráter sagrado da família seja questionado. Talvez assim possamos iniciar um processo de transformação nas relações de gênero, construindo uma sociedade mais democrática. A igualdade entre homens e mulheres não se decreta, se constrói. Uma das deliberações de Beijin é de que eliminar a violência é construir democracia. Porque na democracia a igualdade faz toda a diferença.

Resta a todos nós, um trabalho incessante, em todos os lugares e ocasiões, da academia à associação de bairro, passando pelas igrejas, mídia, de mostrar que o processo de fazer homens e mulheres, a designação de seus papéis sociais, a hierarquização entre os dois sexos subordinando o gênero feminino ao masculino são construções, invenções históricas. Nada de natureza passa por aí. O que há sim é um trabalho entre práticas e discursos, de demonstrar a natureza dos sexos e com isso a sua permanência.

Demonstrar sua construção é um trabalho pedagógico, portanto. A educação que mulheres e homens recebem e o comportamento que apresentam em sociedade são um fenômeno cultural que pode e deve ser mudado. Desconstruir os discursos que estabeleceram historicamente o que é ser homem e o que é ser mulher é uma tarefa urgente e libertadora. Se nem sempre foi assim, se é uma construção histórica, entremeada de relações de poder/saber, podemos fazer e pensar diferente do que pensamos. Podemos pensar que os direitos humanos aplicam-se a todos os humanos, homens e mulheres, e fazer um mundo diferente onde a liberdade possa ser desfrutada por todos os humanos e humanas.

\section{Fronteira geográficA E CULTURAL E A DESIGUALDADE DE GÊNERO}

É indiscutível a participação das mulheres como um componente fundamental no debate das políticas públicas, mas mesmo assim existe um longo caminho de superaração das velhas idéias economicas que ignoravam Hist. R., Goiânia, v. 19, n. 3, 2014 
o feminino e alijavam as mulheres das grandes questões da economica global. O feminismo como movimento social e politico propõe como estratégia essencial à construção das bases de outra economia, a agregação de alguns elementos e teorias pela economia solidária. O principal objetivo é o de que a economia solidária pode assumir a agenda feminista, rompendo com a separação dicotômica entre produção e reprodução, com a divisão sexual do trabalho, ampliando a noção e o conceito de trabalho. Superar a hierarquia entre as atividades mercantis e não mercantis que atendam as necessidades da subsistência humana é fundamental para compreender a desvalorização do mundo da reprodução e das tarefas que o envolvem, até então consideradas secundárias, efêmeras e sem importância.

As mulheres rurais e indígenas, embora enfraquecidas por uma situação de dependência históricamente construida, são as principais protagonistas na manutenção da vida nas comunidades. Há um fato que ninguém contesta - as mulheres já experimentam o poder de resolver por si mesmas as situações que as afetam e formulam soluções estratégicas e praticas a partir do seu empoderamento. Apesar disso continuam sofrendo as marcas da desqualificação e da desigualdade.

Muitas vezes em nome do argumento do respeito a diversidade cultural e de certas 'práticas tradicionais' muitas mulheres sofrem em nome da 'tradiçao' violaçoes dos diretos humanos, uma violência culturalmente institucionalizada sobre os seus corpos, como o abuso sexual e outras praticas de violencias.

Teorizar estas questões apresenta-se como um desafio ao pensamento feminista. Desconstruir o discurso que a cultura reforçou para analisar a difícil relação da mulher com a natureza -, sem dúvida diferente dos homens - mas que deve ser explicado a partir do ponto em que a mulher foi colocada, e não o contrário. Se a feminilidade é induzida pela divisão de 
papéis, aceitá-la como o principio da cultura é também aceitar a divisão sexual do trabalho. ${ }^{3}$

Compreender o trabalho invisível realizado pelas mulheres na execução das atividades de reprodução não mercantis leva a ampliar a noção de trabalho para além da tradicional visão do "trabalho produtivo mercantil". Ampliar o conceito de trabalho considerá-lo em sua totalidade e em todas as suas esferas contribui para a igualdade de atividades de quem as executa, avançando em direção a superação da divisão sexual do trabalho. O horizonte da igualdade, da autonomia e da superação das relações de poder dos homens sobre as mulheres apresenta a pauta de transformações das relações interpessoais, da luta por mudanças estruturais na sociedade, na economia, na cultura. Falar em Direitos Humanos na atualidade é tão somente inserir com dignidade e respeito todo os sujeitos que compõem a sociedade.

As mulheres indígenas e camponesas estão subsumidas em práticas discursivas e não discursivas duplamente excludentes. Entendendo aqui as práticas discursivas mais amplas do que simplesmente modos de fabricação de discursos. Tomando corpo no conjunto das técnicas, das instituições, dos esquemas de comportamento, nas formas pedagógicas que, por sua vez, as impõem e mantém. As práticas não discursivas são também parte do discurso, à medida que identificam tipos e níveis de discurso, definindo regras que ele de algum modo atualiza. Indígenas e camponesas são ainda consideradas menores por serem mulheres, e também menores por fazerem parte de grupos sociais marginalizados. Romper estas barreiras apresenta-se como uma tarefa urgente e necessária, fundamental para todos aqueles que apostam num mundo mais humano e democrático. 


\section{CONCLUSÃo}

Olympe de Gouges, apresentou aos Estados Gerais franceses em 1791 A Declaração dos Direitos da Mulher e da Cidadã1, como uma resposta à Declaração dos Direitos do Homem e do Cidadão, reconhecida como momento fundador dos modernos direitos da liberdade e a igualdade. Após lutar juntamente com os homens pelos ideais burgueses da Revolução Francesa, não sentiu o seu sexo representado na declaração universal. 0 documento que apresenta se revela de particular importância por conter afirmações e reivindicações das mulheres em termos de direito e denunciar a conotação parcial do sujeito masculino.

Sua declaração transforma-se no primeiro manifesto público em favor dos direitos da mulher. No contexto dramático da Revolução Francesa, por causa da sua crítica pública aos valores patriarcais e à violência do poder jacobino, ela foi guilhotinada em 1793. Segundo os revolucionários franceses, Olympe seria guilhotinada por dois "pecados": querer ser um homem de estado e trair a natureza de seu sexo.

Ser um homem de estado era ultrapassar a barreira do privado e adentrar no mundo público da política e do poder, masculino por excelência; trair a natureza de seu sexo era escapar das armadilhas históricas destinadas ao feminino. A "natureza feminina" destinava-a somente ao casamento e à maternidade.

Quando falamos em história das mulheres, lembramos sempre que a representação da diferença sexual deve pouco à ciência e quase tudo à política e à cultura. Por este motivo a categoria de análise gênero é tão importante. No caso francês, a escolha da representante simbólica da Revolução Francesa recai sobre Marianne, uma mulher linda em véus brancos esvoaçantes, efêmera e irreal. À mulher combativa, real e libertária resta a guilhotina. 
Quando Olympe de Gouges escreve a declaração da Cidadã é contra este bloco de discursos poderosos que se impõe. Rousseau ao inventar a rainha do lar, o anjo do lar, figura imaginária que resiste até os dias atuais, teve a adesão da maioria das mulheres. Com seus órgãos internos esmagados pelos espartilhos, as anquinhas que the tolhiam os movimentos, os coques impecáveis, as mulheres ocidentais eram o reflexo de Sofia, figura literária e imaginária, criada por Rousseau como a companheira do modelo de cidadão, Emílio.

As práticas discursivas não são pura e simplesmente modos de fabricação de discursos. Elas tomam corpo, no conjunto das técnicas, das instituições, dos esquemas de comportamento, dos tipos de transmissão e difusão, nas formas pedagógicas que, por sua vez, as impõem e mantém. As práticas não discursivas são também parte do discurso, à medida que identificam tipos e níveis de discurso, definindo regras que ele de algum modo atualiza.

Os discursos que nomearam o masculino e o feminino se inculcaram profundamente na cultura ocidental e estabeleceram a preponderância do masculino e a subordinação do feminino. Michel Foucault encara o discurso como prática social. Em sua célebre aula $A$ Ordem do Discurso, sublinha a idéia de que o discurso é produzido em razão das relações de poder. Por outro lado o discurso numa relação saber $\mathrm{x}$ poder produz realidade, produz verdade:

Ora, essa vontade de verdade, como os outros sistemas de exclusão, apóia-se sobre um suporte institucional: é ao mesmo tempo reforçada e reconduzida por todo um compacto conjunto de práticas como a pedagogia, é claro, como o sistema de livros, da edição , das bibliotecas, como as sociedade de sábios de outrora, os laboratórios hoje. Mas ela é reconduzida, mais profundamente sem dúvida, pelo modo como o saber é aplicado em uma sociedade, como é valorizado, distribuído, repartido e de certo modo atribuído (FOUCAULT, 1996, p.17). 
Combater estes discursos que transformaram-se em práticas discursivas e não discursivas é um trabalho árduo que exige a atenção de todas as instituições. Família, escola, mídia, igreja e outras devem reconhecer o trabalho "eficiente" que foi efetivado durante séculos para subordinar e excluir as mulheres, e proporcionar a sua desconstrução. Abrir os discursos, mostrar como e quando foram arquitetados, desconstruí-los, é uma tarefa árdua e difícil e necessária. A radical desigualdade entre os sexos - a violência contra a mulher por ser transnacional e atravessar todas as categorias como classe, raça, etnia, geração, ter se transformado em chaga mundial e caso de saúde pública, necessita a convocação dos direitos humanos para combatê-la.

Devemos acreditar que os direitos humanos aplicam-se a todos os humanos, homens e mulheres, e fazer um mundo diferente onde a liberdade possa ser desfrutada por todos os humanos e humanas.

\section{Notas}

(Endnotes)

1 Para Badinter esta é a tese que Freud desenvolverá em 1931: “A mulher, é preciso bem confessá-lo, não possui num alto grau o sentido da justiça, o que deve estar ligado, provavelmente, à predominância da inveja no seu psiquismo". Cf. BADINTER, 1991, p. 14.

2 Lei Maria da penha cria mecanismos para coibir a violência doméstica e familiar contra a mulher, nos termos do $\& 8^{\circ}$ do artigo 226 da Constituição Federal, da Convenção sobre a Eliminação de Todas as Formas de Discriminação contra as Mulheres e da Convenção Interamericana para Prevenir, Punir e Erradicar a Violência contra a Mulher e ainda dispõe sobre a criação de juizados de Violência Doméstica e Familiar contra a Mulher, altera o Código de Processo Penal, o Código Penal e a Lei de Execução Penal, dentre outras providências.

3 Uma discussão interessante é a do ecofeminismo e das mulheres e meio ambiente. Inúmeras obras estão disponíveis sobre o tema. Também continua atual a análise da Carole Pateman em o Contrato Sexual, sobre as mulheres e a divisão entre o público e o privado. assegura que existiu um contrato sexual antes do contrato social. Este contrato definiu que as mulheres seriam confinadas no mundo privado, visto como politicamente irrelevante, e os homens atuariam no público, lugar da liberdade civil, da política e do poder por excelência. A diferença sexual se converte em uma diferença política. 
BIBLIOgRAFIA

ALVAREZ, Ana de Miguel (1994). Como leer a John Stuart Mill. Madrid: Júcar. BADINTER, Elisabeth (1991). Palavras de Homens (1790-1793). Rio de janeiro: Nova Fronteira.

BONACCHI, Gabriela; GROPPI, Ângela (org.) (1995). O Dilema da Cidadania. Direitos e Deveres das mulheres. São Paulo: Unesp.

COLLING, A. M. (1997) A resistência das mulheres à ditadura militar no Brasil. Rio de Janeiro: Rosa dos tempos.

(2004). A construção histórica do masculino e do feminino. In: Gênero e Cultura. Questões contemporâneas. Porto Alegre: Edipucrs, (pp.13-38)

(2011). Direitos humanos para que humanos? In: Fundamentos para educação em Direitos Humanos. São Leopoldo: Sinodal/EST.

CONDORCET (1991). Sobre a admissão das mulheres ao direito de cidadania. In: Badinter, Elisabeth (Org.) Palavras de Homens (1790-1793). Rio de Janeiro: Nova Fronteira.

(1991). A instrução das mulheres. In: Badinter, Elisabeth (Org.) Palavras de Homens (1790-1793). Rio de Janeiro: Nova Fronteira.

DRIVER, Stephanie Schwartz. (2004). A Declaração de Independência dos Estados Unidos. Rio de Janeiro: Jorge Zahar Editor.

FOUCAULT, M. (1979). História da sexualidade. A vontade de saber. Rio de Janeiro: Graal.

(2002). La Hermenéutica del Sujeto. Buenos Aires: Fondo de Cultura Economica de Argentina.

(1996). A Ordem do Discurso. São Paulo: Edições Loyola.

GAY, Peter (1988). Freud. A Educação dos Sentidos. A experiência burguesa. Da rainha Vitória a Freud. Rio de Janeiro: Companhia dsas Letras.

HÉRITIER, F. (1996). Masculino/Femenino. El pensamiento de la diferencia. Traducción de Vicente Villacampa. Barcelona: Ariel.

HUNT, Lynn (2009). A invenção dos direitos humanos: uma história. São Paulo: Companhia das Letras. 
MILL, John Stuart. (2006). A Sujeição das Mulheres. São Paulo: Escala.

PALLA, Maria Antônia (1985). O essencial sobre a Condição feminina. Lisboa: Imprensa Nacional/Casa da Moeda.

PERROT, M. (2005). As Mulheres e os silêncios da História. Bauru, EDUSC.

ROUSSEAU, Jean-Jaques (1992). Emílio ou Da Educação. Rio de Janeiro: Bertrand Brasil.

SCOTT, J. (1998). La citoyenne paradoxale. Les féministes françaises et les droits de l'homme. Paris, Albin Michel.

(1995), Gênero: uma categoria útil de análise histórica. In: Educação \& Realidade. Porto Alegre:UFRGS.

TEDESCHI, Losandro (2012) As mulheres e a história. Uma introdução teórico metodológica. Dourados/MS: Editora UFGD. 
